\title{
Aggregation of human granulocytes by Staphylococcus aureus lipase
}

\author{
J. ROLLOF, E. VINGE*, P. NILSSON-EHLEt and J. H. BRACONIER
}

Departments of Infectious Diseases, "Clinical Pharmacology and tClinical Chemistry, University Hospital of Lund, S-22185 Lund, Sweden

\begin{abstract}
Summary. The effects of purified extracellular lipase from Staphylococcus aureus on human granulocytes were studied in vitro with a turbidimetric technique. Within the concentration range 0.6-4.4 $\mu \mathrm{g} / \mathrm{ml}$, lipase caused monophasic aggregation accompanied by the release of lactoferrin; the corresponding concentrations of the solvent in which it was suspended, Triton X100, had no effect. Lipase-induced aggregation did not occur in the presence of autologous plasma.
\end{abstract}

\section{Introduction}

Polymorphonuclear neutrophil leucocytes (granulocytes) provide an important part of the host defence against bacterial infections. Pus formation is a classical sign of bacterial, in particular staphylococcal, infections. The high incidence of such infections in individuals with intracellular defects ${ }^{1}$ and in granulocytopenia, underlines the crucial role of these cells. Granulocytes play an important role in the inflammatory process; their activation, and subsequent secretion of lysosomal enzymes, may contribute to tissue destruction.

Earlier studies have shown that extracellular lipase from Staphylococcus aureus interacts with human granulocytes. ${ }^{2}$ Scanning electron microscopy showed alterations in the cell surface. Lipase had a chemotactic activity per se and pre-incubation of granulocytes with lipase enhanced the directed movement of the cells. Higher concentrations of lipase caused a progressive inhibition of granulocyte chemotaxis. Phagocytic killing of $S$. aureus by granulocytes pre-incubated with lipase was also reduced; this was mainly a result of reduced bacterial uptake, but some decrease in intracellular killing was also found. During these studies we observed that the lipase caused aggregation of granulocytes. This phenomenon was studied quantitatively in the present investigation.

\section{Materials and methods}

\section{Lipase}

Extracellular lipase from $S$. aureus strain TEN 5 was purified as described earlier $;^{3}$ this strain was

Received 4 Sept. 1990; revised version accepted 10 April 1991. isolated from a patient with toxic epidermal necrolysis, and was originally supplied by C.G. Gemmell, University of Glasgow. After purification, the lipase showed only one protein band on sodium dodecyl sulphate-polyacrylamide gel electrophoresis (SDSPAGE) with the sensitive silver staining technique, and only one peak of lipase activity and protein after gel filtration on Sephadex G-200. The purified enzyme preparation had a protein content of $250 \mu \mathrm{g} / \mathrm{ml}$, and was suspended in a $0.05 \mathrm{M}$ Tris- $\mathrm{HCl}$ buffer, $\mathrm{pH} 8.0$, with $2 \mathrm{M} \mathrm{KCl}$ and Triton X100 0.3\%. Heat inactivated lipase $\left(100^{\circ} \mathrm{C}, 120 \mathrm{~min}\right)$ was used in some experiments. The same buffer without lipase was used as control. Before the experiments, all preparations were dialysed against $0 \cdot 15 \mathrm{M} \mathrm{NaCl}$. All dilutions of lipase or buffer were made with $0 \cdot 15 \mathrm{M} \mathrm{NaCl}$.

\section{Granulocytes and plasma}

Human granulocytes were prepared from peripheral blood donations with some modification ${ }^{4}$ of the method described by Böyum ${ }^{5}$ of centrifugation on Isopaque-Ficoll and erythrocyte lysis with $\mathrm{NH}_{4} \mathrm{Cl}$ $0.87 \%$. The cells were diluted in Hanks's Balanced Salts Solution buffered with HEPES, as described earlier, to a concentration of $1.4 \times 10^{7}$ cells $/ \mathrm{ml}^{4}$ The same buffer was used for further dilutions to final incubation concentrations. The plasma used in some experiments was prepared from the same donor and at the same time as the granulocytes.

\section{Aggregation tests}

Granulocyte aggregation was studied at $37^{\circ} \mathrm{C}$ in a Chronolog 540-aggregometer with a Hitachi recorder, with stirring at $1000 \mathrm{rpm} ; 450 \mu \mathrm{l}$ of the granulocyte suspension (final concentration 3200 cells/ $\mu$ ) was added to a siliconised glass cuvette. The light trans- 
mission values through the cell suspension and through cell-free buffer were set at 10 and 90 , respectively, on the chart scale. After equilibration for 1-2 min, $25 \mu \mathrm{l}$ of the purified lipase preparation, dilutions of lipase, or buffer were added, and the change in light transmission from the base-line (delta LT, scale units) was recorded over the next $4 \mathrm{~min}$. For the concentration-response evaluation, the change in light transmission after $4 \mathrm{~min}$ was plotted against the final concentration of lipase and Triton X100, respectively. In some experiments, $25 \mu \mathrm{l}$ of lipase mixed with an equal volume of autologous plasma, was added. Tests were performed in duplicate in each separate experiment. To avoid interactions with cytochalasin B, which may amplify but also delay the neutrophil response, ${ }^{6,7}$ this agent was not used.

\section{Lactoferrin}

Granulocytes were incubated with lipase or buffer as described above. After $5 \mathrm{~min}$, the cells were separated by centrifugation and the cell-free supernate was collected and stored at $-20^{\circ} \mathrm{C}$ until analysed for lactoferrin as described by Olsson et al. ${ }^{8}$ All measurements were made in triplicate.

\section{Statistical analysis}

Student's $t$-test (two-tailed) for unpaired data was used for statistical calculations.

\section{Results}

Lipase from $S$. aureus at final concentrations of $\leqslant$ $0.132 \mu \mathrm{g} / \mathrm{ml}$ did not induce granulocyte aggregation; higher concentrations of lipase caused aggregation. The addition of lipase at a final concentration of $1.32 \mu \mathrm{g} / \mathrm{ml}$ resulted in a monophasic low-amplitude reaction (fig. 1). The same pattern was seen with lipase concentration up to $13.2 \mu \mathrm{g} / \mathrm{ml}$, which induced a biphasic, high-amplitude response (fig. 1). Heat inactivated lipase gave the same reactions.

Buffer without lipase served as a negative control. When pure buffer with Triton X100 (final concentration $0.016 \%$, corresponding to the Triton content of samples with lipase $13.2 \mu \mathrm{g} / \mathrm{ml}$ ) was tested, the granulocytes displayed instant maximal, high-amplitude aggregation (fig. 2). With this concentration of Triton, the change in light transmission 4 min after adding the buffer was significantly greater than that caused by the corresponding lipase solution (fig. 3). When the concentration of Triton was reduced to $0.008 \%$, there was still a high-amplitude, but slow aggregatory response (fig. 2). At final concentrations of $0.005 \%$ and lower (corresponding to lipase $\leqslant 4.4 \mu \mathrm{g} /$ $\mathrm{ml}$ ), Triton X100 had virtually no effect on aggregation (fig. 3). Thus, lipase $1.32 \mu \mathrm{g} / \mathrm{ml}(\mathrm{n}=5)$ consistently caused a greater response than the buffer at the corresponding dilution $(n=3)(p=0.0013)$. When

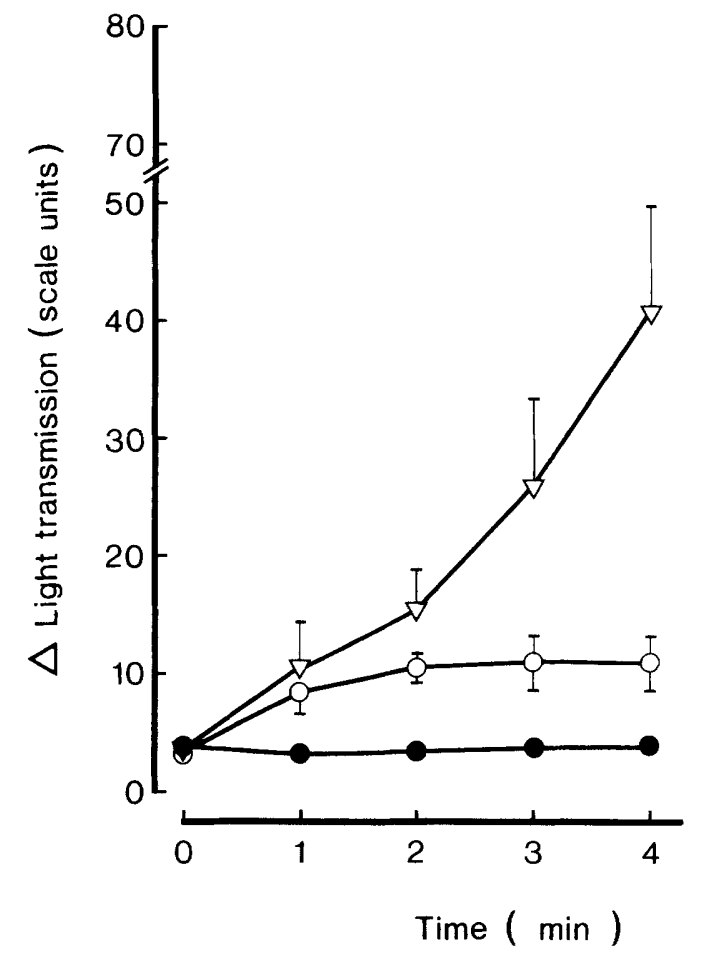

Fig. 1. Change in light transmission through granulocyte suspensions immediately and up to $4 \mathrm{~min}$ after the addition of staphylococcal lipase at three different concentrations: $0.13 \mu \mathrm{g} / \mathrm{ml}(\mathrm{n}=2)$; $\bigcirc-\bigcirc 1.32 \mu \mathrm{g} / \mathrm{ml}(\mathrm{n}=5) ; \nabla-\nabla 13.2 \mu \mathrm{g} / \mathrm{ml}(\mathrm{n}=4)$; mean results are given; bars represent $\mathrm{SD}$.

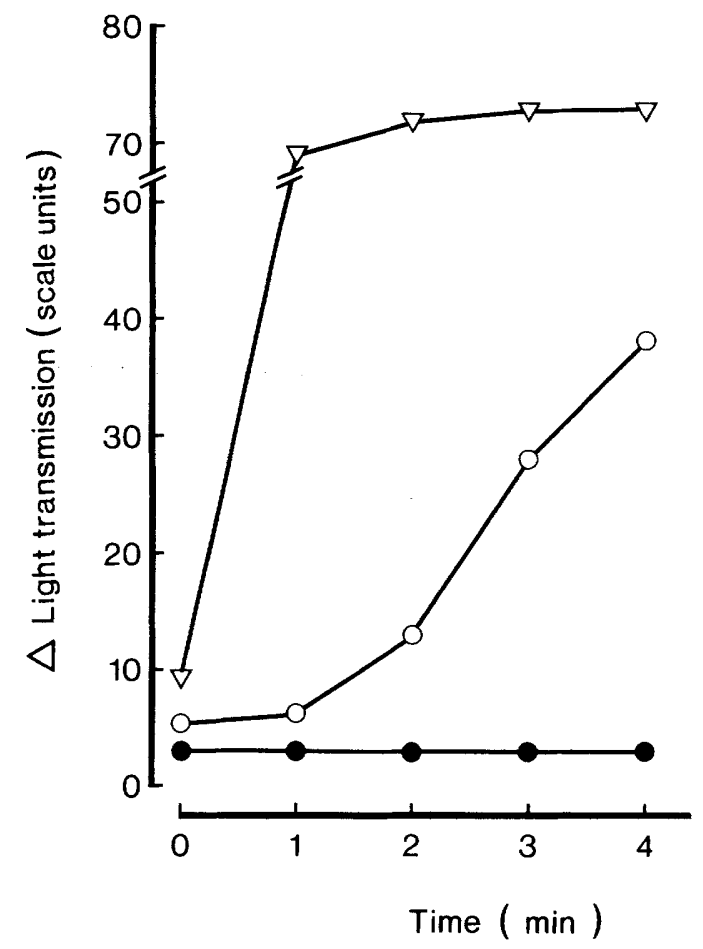

Fig. 2. Change in light transmission through granulocyte suspensions immediately and up to $4 \mathrm{~min}$ after addition of buffer containing Triton X100, at three different concentrations: [number of experiments within brackets.] $0.002 \%(n=3) ; \bigcirc-00.008 \%$ $(n=2) ; \nabla-\nabla 0.016 \%(n=2) ;$ mean results are given.

lipase was mixed with an equal volume of autologous plasma, to a final concentration of $6.6 \mu \mathrm{g} / \mathrm{ml}$, no aggregation was recorded.

As an indication of granulocyte degranulation, 


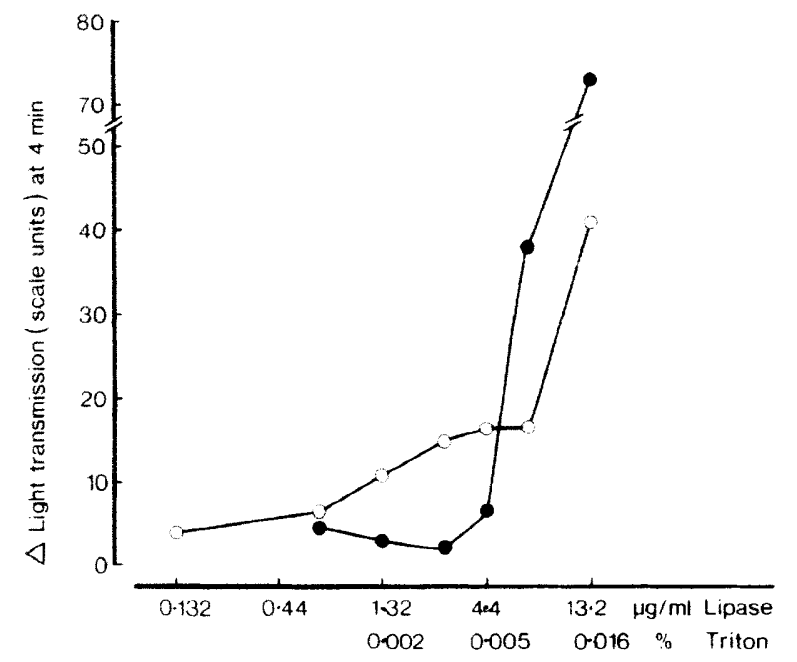

Fig. 3. Dose-response curve showing the effects of staphylococcal lipase, and its corresponding buffer containing Triton $\mathrm{X} 100$, on granulocyte aggregation as determined by change in light transmission through granulocyte suspensions $4 \mathrm{~min}$ after addition of lipase or buffer: $\mathrm{O}-\mathrm{O}$ lipase : Triton $\mathrm{X} 100$.

lactoferrin was measured in supernates from incubation mixtures. Granulocytes incubated with buffer released $18 \mu \mathrm{g}$ of lactoferrin $/ 10^{6}$ cells. By comparison with 1.32 or $13.2 \mu \mathrm{g}$ of lipase $/ \mathrm{ml}$, lactoferrin release was 42 and $51 \mu \mathrm{g}$ respectively.

\section{Discussion}

Staphylococcal lipase in the range $0 \cdot 132-13 \cdot 2 \mu \mathrm{g} / \mathrm{ml}$ stimulated concentration-dependent neutrophil granulocyte aggregation. The effect had a rapid onset, and appeared consistently in each preparation of granulocytes.

It was not possible to establish a complete doseresponse curve with a maximum response to the lipase in the concentration range tested because of interference by Triton X100 in the suspending buffer. Triton is needed to solubilise the enzyme and for the stability of the purified protein. ${ }^{3}$ However, Triton is also known to cause disintegration of cell membranes. At a $1 \%$ solution it is employed in standard procedures for skinning muscle fibres, but even lower concentrations disturb cell-membrane integrity. ${ }^{9}$ It is reasonable to assume that the second phase of the aggregatory response to the highest concentration of lipase tested (final concentration $13.2 \mu \mathrm{g} / \mathrm{ml}$ ), and the prompt response to the corresponding buffer, were due to the presence of Triton X100 (final concentration $0.016 \%$ ). However, at lower concentrations of lipase, when the corresponding buffer had little or no effect (fig. 3), a consistent monophasic aggregatory response was elicited (fig. 3). Therefore we interpret the reaction of the cells to lipase $0.6-4.4 \mu \mathrm{g} / \mathrm{ml}$ as true aggregation. This low-amplitude monophasic aggregation appears to be in the same range as that previously reported for leukotriene $\mathrm{B}_{4}\left(\mathrm{LTB}_{4}\right)$ and formyl-methionyl-leucylphenylalanine (fMLP). ${ }^{6}$ The mechanism behind the aggregatory response to lipase remains to be elucidated, but since heat inactivated lipase had a similar effect, it does not appear to depend primarily on the enzymatic activity of the protein. It could be ascribed the hydrophobic character of the protein. The finding that the length of incubation was not critical for the effect of lipase (fig. 3) is consistent with a non-enzymic mode of action.

The significance of the effects of lipase on granulocytes in vivo is unclear, partly because the levels of staphylococcal lipase in the mammalian body, especially at the site of infection, are unknown. That lipase is present is demonstrated by the presence of serum anti-lipase IgG detectable by ELISA. ${ }^{10}$ Staphylococcal strains from deep infections produce more lipase than strains from superficial locations. ${ }^{11}$ Extrapolation of data on the release of lipase from such strains in culture indicates that the amounts of lipase produced greatly exceed those necessary to elicit an aggregatory response in granulocytes.

Increased leucocyte adhesiveness and tendency to clump during phagocytosis have been recognised. ${ }^{12}$ Aggregation of granulocytes after exposure to C5a has been associated with degranulation and release of predominantly secondary granule contents. Because degranulation and secretion from granulocytes could interact with lipase in the aggregation process, we measured lactoferrin as a marker for activation of the granulocytes. The minimal amount of lipase, eliciting monophasic aggregation of granulocytes, produced an increased release of lactoferrin. The secondary granules, containing lactoferrin, are rapidly mobilised by activation of the cells. The amount of lactoferrin released in this experiment seems to indicate a high degree of activation. We have found that phagocytosis of opsonised bacteria released about twice the amount of lactoferrin than that produced in buffer (unpublished observations). Release of granule proteins may be of pathophysiological importance, contributing to the tissue destruction seen in staphylococcal infections. The release of lactoferrin may be essential for the aggregation of granulocytes. Lactoferrin by itself induces aggregation of granulocytes which can be prevented by anti-lactoferrin. ${ }^{13}$ Thus, lactoferrin may add to the aggregation induced by lipase. Lactoferrin is not likely to produce the effect alone, because aggregation does not occur with granulocytes and $S$. aureus.

As well as lipase, other products from $S$. aureus may contribute to the tissue damage. Leucocidin is an extracellular staphylococcal product that has a nonspecific effect on human granulocytes, causing secretion of potentially toxic granule enzymes. ${ }^{14}$ It is likely that pronounced aggregation of granulocytes may reduce their phagocytic capacity and interfere with host defence. Further studies are warranted to clarify the significance of the action of staphylococcal lipase on human cells.

We thank J. Richter, Department of Medicine, University of Lund, for measuring lactoferrin. 


\section{References}

1. Singer C. Infections in patients with neoplastic diseases. In: Grieco ME (ed) Infections in the abnormal host. New York, Yorke Medical Books. 1980: 546-584.

2. Rollof J, Braconier JH, Söderström C, Nilsson-Ehle P. Interference of Staphylococcus aureus lipase with human granulocyte function. Eur J Clin Microbiol Infect Dis 1988; 7: 505-510.

3. Rollof J, Hedström SA, Nilsson-Ehle P. Purification and characteristics of a lipase from Staphylococcus aureus. Biochim Biophys Acta 1987; 921: 364-369.

4. Braconier JH, Odeberg H. Granulocyte phagocytosis and killing of virulent and avirulent serotypes of Streptococcus pneumoniae. J Lab Clin Med 1982; 100: 279-287.

5. Böyum A. Separation of leucocytes from blood and bone marrow. Scand J Clin Lab Invest 1968; 21 Suppl 97: 1-109.

6. Ringertz B. Neutrophil aggregation-factors modulating stimulus-specific responses. APMIS Sect C 1986; 94: 1-9.

7. Palmblad J, Gyllenhammar H, Ringertz B, Nilsson E, Cottell B. Leukotriene $B_{4}$ triggers highly characteristic and specific functional responses in neutrophils: studies of stimulus specific mechanisms. Biochim Biophys Acta 1988; 971 : 92102.
8. Olsson J, Olofsson T, Ohlsson K, Gustavsson A. Serum and plasma myeloperoxidase, elastase and lactoferrin content in acute myeloid leukaemia. Scand J Haematol 1979; 22: $397-406$.

9. Thelestam M, Möllby R. Determination of toxin-induced leakage of different-size nucleotides through the plasma membrane of human diploid fibroblasts. Infect Immun $1975 ; 11$ : $640-648$.

10. Christensson B, Fehrenbach FJ, Hedström SÅ. A new serological assay for Staphylococcus aureus infections: detection of IgG antibodies to $S$. aureus lipase with an enzyme-linked immunosorbent assay. $J$ Infect Dis 1985; 152: 286-292.

11. Rollof J, Hedström SA, Nilsson-Ehle P. Lipolytic activity of Staphylococcus aureus strains from disseminated and localized infections. APMIS Sect B 1987; 95: 109-113.

12. Klebanoff SJ, Clark RA. The neutrophil: function and clinical disorders. Amsterdam, North Holland Publishing Co. 1978: 191.

13. Oseas R, Yang H-H, Baehner RL, Boxer LA. Lactoferrin: a promoter of polymorphonuclear leukocyte adhesiveness. Blood 1981; 57: 939-945.

14. Woodin AM. The leukocidin-treated leucocyte. In: Dingle JT (ed) Lysosomes in biology and pathology, vol 3. Amsterdam, North Holland Publishing Co. 1973: 395-422. 